\title{
COMPARATIVE STUDY FOR ESTIMATION OF FETAL WEIGHT BY CLINICAL \& ULTRASONOGRAPHICAL METHODS IN TERM PATIENTS
}

\author{
Karuna Ratwani ${ }^{1}$, Chandrakant S. Madkar², Hemant G. Deshpande ${ }^{3}$, Sumit Jethani ${ }^{4}$
}

\section{HOW TO CITE THIS ARTICLE:}

Karuna Ratwani, Chandrakant S. Madkar, Hemant G. Deshpande, Sumit Jethani. "Comparative Study for Estimation of Fetal Weight by Clinical \& Ultrasonographical Methods in Term Patients". Journal of Evolution of Medical and Dental Sciences 2014; Vol. 3, Issue 10, March 10; Page: 2553-2560,

DOI: $10.14260 /$ jemds/2014/2172

ABSTRACT: BACKGROUND: Accurate determination of fetal birth weight prior to delivery can have significant bearing on management decision in labor, thereby markedly improving perinatal outcome. OBJECTIVE: To assess fetal weight in term pregnancy by different clinical and ultrasonographical methods. MATERIALS AND METHODS: The study was conducted in Obstetrics and Gynecology department of Dr. D.Y. Patil Medical College, Pimpri, Pune. Two hundred (200) women were selected and studied for a period of one year based on convenience sampling from October 2011 to September 2013.The fetal weight was estimated a week prior to the delivery by both ultrasound and clinical examination. Various formulae's for estimation of fetal weight were applied based on Ultrasound and clinical parameters. All results arising from different formulas were studied and suitable statistics was applied and compared to have clear idea regarding results. RESULTS: All results arising from different formulas were studied by Descriptive statistics and compared with Actual weight at the time of delivery (gold standard). A box plot was used to differentiate various methods used for estimation of fetal weight, It shows that Johnson, Dawn formula and weight in gms (Dare's) formula corresponds with the base line indicating that they can predict birth weight correctly and among these Johnson showed promising results, whereas formulas like Campbell, Comb's, Hadlock and Warsof didn't predict birth weight as accurately as the three clinical methods used, thus in our study it can be seen that clinical methods are better predictors of birth weight than ultrasonographic methods. CONCLUSIONS: In our study it was observed that Clinical methods used for estimation of fetal birth weight was found to be by far simple and reliable methods in estimation of fetal birth weight than Ultrasonographic estimation methods and thus holds importance in day to day practice especially in countries like us where still a large group of population resides in rural areas.

KEYWORDS: Ultrasound, weight, fetal, age.

INTRODUCTION: Fetal weight, in conjunction with gestational age, is an important indicator of pregnancy outcome. ${ }^{1}$

During the last decade, estimated fetal weight has been incorporated into the standard routine antepartum evaluation of high risk pregnancies and deliveries. For instance, management of diabetic pregnancy, vaginal birth after a previous caesarean section and intrapartum management of fetuses presenting by breech will be greatly influenced by estimated fetal weight. ${ }^{2}$

It has become increasingly important especially for the prevention of prematurity, evaluation of pelvic disproportion before induction of labor and detection of intrauterine growth restriction. ${ }^{3}$ Categorization of fetal weight into either small or large for gestational age may lead to timed obstetric interventions that collectively represent significant departure from routine antenatal care.4, 5, 6

There are different algorithms based on combination of various ultrasound parameters like biparietal diameter (BPD), head circumference (HC), abdominal circumference (AC), femur length 
(FL), anterior posterior trunk diameter (APTD), transverse trunk diameter (TTD), fetal trunk cross sectional area (FTA)2, which are used singly or in combinations.

The different algorithms used worldwide are Hadlock's formula, Shepard formula, Tokyo University formula, Campbell, Hansman, Sabbagha, Warsof, etc.

Thus estimating fetal weight antenatally is of utmost important to the obstetricians so that:

It can have preventive measures to deal with respiratory distress syndrome (RDS), hypoglycemia in a low birth weight (LBW) neonate; anticipate problems of shoulder dystocia in macrosomic fetus. Thus reduce the risk of mortality and morbidity to mother and neonate ${ }^{7}$.

Accurate estimation of fetal weight is of paramount importance in the management of labor and delivery. During the last decade, estimated fetal weight has been incorporated into the standard routine ante partum evaluation of high-risk pregnancies and deliveries. For instance, management of diabetic pregnancy, vaginal birth after a previous caesarean section, and intrapartum management of fetuses presenting by the breech will be greatly influenced by estimated fetal weight. ${ }^{8}{ }^{9}$ During the initial era or before the birth of science fetal weight estimation was more a kind guess work. The cardinal importance of knowledge of the size and shape of the fetal head in order to understand the mechanism of labor was first recognized by Smellie (1752) who also pointed out that it is the biparietal diameter which passes through the narrowest part of the pelvic brim. ${ }^{10}$

MATERIALS AND METHODS: The study was conducted in Obstetrics and Gynecology department of Dr DY Patil Medical College, Pimpri, Pune. It was an Observational study, two hundred (200) women were selected and studied for a period of one year based on convenience sampling and total duration was October 2011 to September 2013.Institutional ethical clearance was obtained prior to conduct the study.

The fetal weight was estimated within a week prior to the delivery by both ultrasound and clinical examination. Various formula's for estimation of fetal weight were applied based on Ultrasound and clinical parameters.

A thorough general physical examination of each patient was done including vital signs, cardiovascular and respiratory tract examination.

The patient was then asked to empty bladder. Abdominal examination was done noting the lie presentation, position amount of head palpable per abdomen (in fifths) and fetal heart. estimation of fetal birth weight was done palpating the various fetal parts palpable.

The symphysio-fundal height and abdominal girth were measured between contractions if in labor, using a flexible, non-elastic, standard sewing tape. Both measurements were performed with the patient lying flat on her back, with her legs extended, and were rounded to nearest centimeter. The fundal height was measured from mid-point of upper border of the pubic symphysis to the highest point of uterine fundus. The upper hand was placed firmly against the top of the fundus with the measuring tape passing between the index and middle fingers and readings were taken from the perpendicular intersections of the tape with fingers. For the abdominal measurements the tape was repositioned to encircle the woman's waist at the level of umbilicus, without applying excessive pressure to tighten the tape around abdomen.

Per Vaginal examination: The pelvic examination performed to evaluate cervical dilatation and the degree of descent of fetal head into the pelvis. The fetus was considered to be at a minus station when the lowermost portion of the fetal head was above ischial spines, at zero station 
(engaged) when the vertex was at level of the spines and at a plus station when it was below this level. Both the measurement abdominal girth and symphysiofundal height and information on fetal station were recorded on individual data sheet and later used to calculate the fetal weight according to the formula proposed by Johnson, dawns and Dare et al.11

The patient was then sent to the Radiology department for an obstetrics ultrasound. All ultrasound scans were performed by resident sinologists with minimum two years' experience in radiology. The ultrasound fetal weight was calculated automatically by ultrasound machine, using Hadlocks reference table, which used the biparietal diameter, head circumference, abdominal circumference and femur length. A printed report on ultrasound examination mentioning all measurements and fetal weight estimation was attached to patients chart. The sonologist did not have any access to patient's data sheet containing clinical measurements. Neither the sonologist nor the pediatrician (who is always present at the time of delivery recorded birth weight) residents were aware that they were being studied (Double blinding nature).

All results arising from different formulas were studied by Descriptive statistics ${ }^{11}$ and applied and compared with the actual birth weight taken at the time of delivery to have clear idea regarding results.

\section{The study consisted of estimation of fetal birth weight using the following eight methods:}

Clinical Methods:

Weight in grams (Dare's Method): Abdominal girth (in $\mathrm{cms}$ ) x Symphysio-fundal height (in $\mathrm{cms}$ ) (AGXSFH)

Abdominal girth was measured at the level of the umbilicus. Symphysio-fundal height or McDonalds measurement was done after correcting the dextro-rotation, from the upper border of symphysis to the height of fundus.

Johnson's Formula: for estimation of fetal weight in vertex presentation is as follows:

Fetal weight $(\mathrm{g})=\mathrm{fH}(\mathrm{cm}) \mathrm{n} \times 155$.

Where $\mathrm{fH}=$ fundal height and

$\mathrm{n}=13$ when presenting part not engaged

$\mathrm{n}=12$ when presenting part at station 0

$\mathrm{n}=11$ when presenting part at station +1

If a patient weighs more than $91 \mathrm{~kg}, 1 \mathrm{~cm}$ is subtracted from the fundal height.

Dawn's formula: Weight (in Gms.) = Longitudinal diameter of Uterus $\mathrm{x}$ (transverse diameter of uterus) ${ }^{2} \times 1.44$.

The measurements were made with pelvimeter DAWT (double abdominal wall thickness) was also measured with pelvimeter. If DAWT was more than $3 \mathrm{cms}$, the excess was deducted from transverse and half the excess is deducted from longitudinal diameter

\section{Ultrasonographic Methods:}

Hadlocks formula using Ultrasound: After head circumference (HC), abdominal circumference (AC), femur length (FL) were measured in centimeters the sonography machine calculated the fetal weight.

It is calculated as $\log _{10} \mathrm{BW}=1.335-0.000034(\mathrm{ACxFL})+0.00316 \mathrm{x}(\mathrm{BPD})+0.0045(\mathrm{AC})$ +0.01623 (FL). 
Shepard formula: $\log _{10} B W=1.7492+0.0166(B P D+)+0.0046(A C)-0.00002646$ (ACxBPD)

Campbell formula: $\mathrm{LnBW}=4.564+0.0282(\mathrm{AC})-0.0000331(\mathrm{AC})^{2}$

Warsof formula: $\mathrm{LnBW}=2.792+0.108(\mathrm{FL})+0.000036(\mathrm{AC})^{2}-0.00027$ (FLXAC)

Combs formula: $\mathrm{BW}=(0.00023718 \mathrm{x} \mathrm{AC} 2 \mathrm{X} \mathrm{FL})+0.03312(\mathrm{HC})^{3}$

The fetal weights are estimated by above eight methods and were compared with actual birth weight post-delivery.

Interviews were taken using structured and pretested questionnaire for study with written informed consent from the patients.

Statistical analysis: Data were entered in MS-EXCEL sheet, compiled and analyzed by Epi Info 6 version and SPSS 17 version by proper statistical tests. P-value of $<0.05$ was considered statistically significant.

Ethical clearance: Institutional ethical committee clearance was obtained prior to conduct the study.

RESULTS: The study was undertaken at Dr DY Patil Medical College, Pune at Department of Obstetrics and Gynecology, 200 singleton pregnancy at > 36 weeks were taken for the study.

Mean and standard deviation of the various formulas used for the estimation of fetal birth weight and mean of actual birth weight at delivery and out the total formulas used Dare et al (wt in gms) method, Johnson and Dawn's having mean weight of $2.89 \mathrm{~kg}$ and $2.86 \mathrm{~kg}$ nearly corresponds with mean of actual birth weight at delivery i.e. $2.90 \mathrm{~kg}$.The standardized mean difference (SMD) expresses the variation of measurement by each of the 8 formulas used in the study relative to the variability observed, it was calculated using following formula i.e.

SMD= Difference in Mean outcome formula used with Actual weight at delivery.

Standard deviation of Formula used.

Therefore from the table below it shows that SMD of Dare et al Method, Johnson and Dawn's was showing least variability in estimating the birth weight of the babies.

\begin{tabular}{|l|c|c|c|c|}
\hline \multicolumn{1}{|c|}{ Formulae } & $\begin{array}{c}\text { Mean } \\
\text { (Wt in Kgs) }\end{array}$ & Standard Deviation & $\begin{array}{c}\text { Co-efficient } \\
\text { of Variation (CV) }\end{array}$ & $\begin{array}{c}\text { Standardized Mean } \\
\text { Difference (SMD) }\end{array}$ \\
\hline Shepard & 2.81 & 0.50 & 17.92 & 0.18 \\
\hline Campbell & 2.51 & 0.45 & 18.13 & 0.86 \\
\hline Hadlock's & 2.54 & 0.33 & 13.13 & 1.09 \\
\hline Warsof & 1.4 & 0.2 & 14 & 7.5 \\
\hline Comb's & 2.5 & 0.48 & 19.5 & 0.83 \\
\hline $\begin{array}{l}\text { Wt. in gms } \\
\text { (Dare method) }\end{array}$ & 2.88 & 0.35 & 12.03 & 0.05 \\
\hline Johnson & 2.89 & 0.44 & 13.03 & 0.02 \\
\hline Dawn's & 2.86 & 0.45 & 15.78 & 0.08 \\
\hline Wt. at Delivery & 2.90 & 0.43 & 14.89 & -- \\
\hline
\end{tabular}


Box plot which is used to compare various formulas with the standard (gold standard) i.e. actual weight at time of delivery, the base line indicates actual weight during delivery. To calculate box plot the difference between the actual birth weight and formulas used to estimate fetal birth weight were calculated individually keeping actual weight at delivery as gold standard and they were then plotted. Boxes in the red represents formulas used to estimate fetal birth weight. In this graph it can be seen that Johnson, Dawn formula and weight in gms(Dare's) formula corresponds with the base line this indicate that they can predict birth weight correctly more specifically Johnson, where formulas like camp, comb's, hadlock and Warsof underestimated the weight as the boxes are below the base line. The circle represent outliers in all the formulas which both underestimated and overestimated (above base line) in few subjects. The numbers indicates serial no when plotted continuously on the excel sheet for example each formula was used for 200 cases, therefore total 8 formulas were used which account to 1600 .

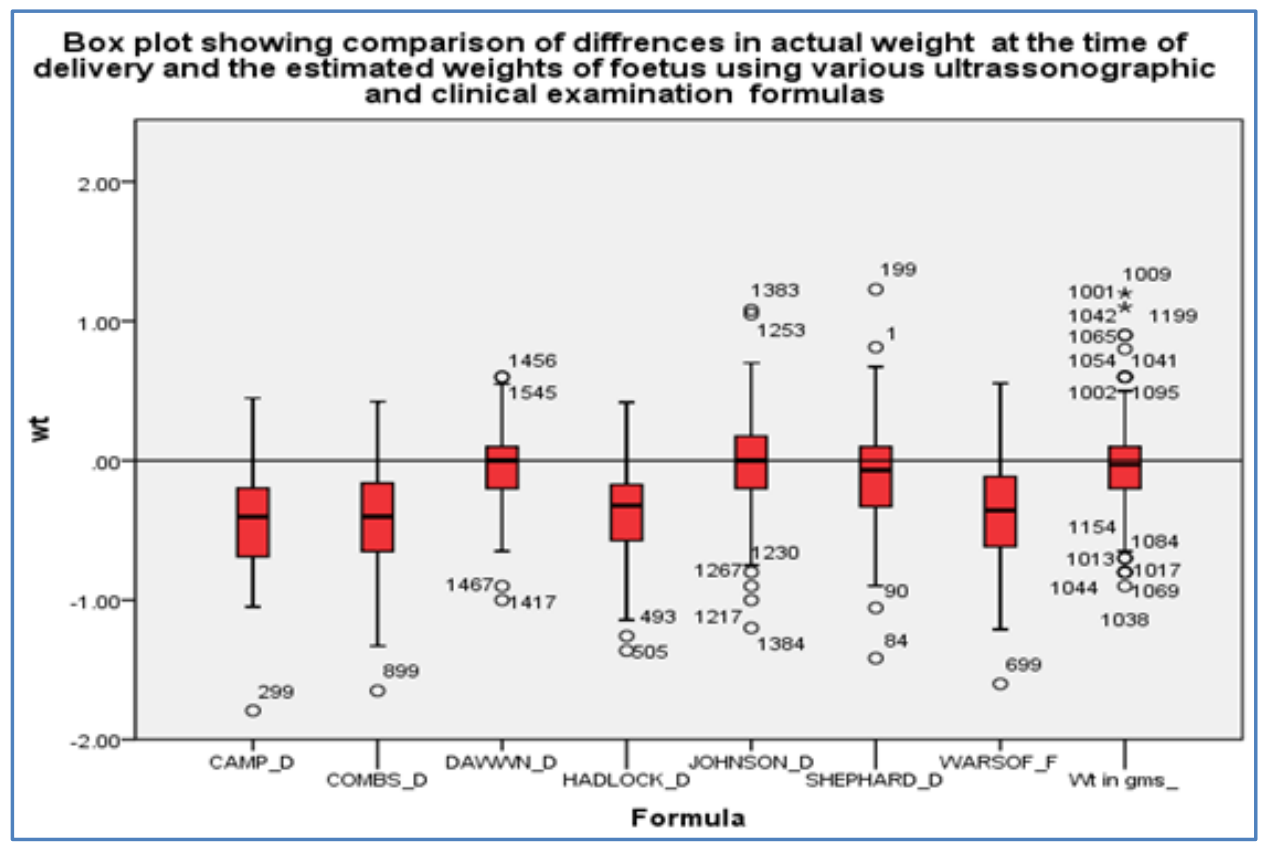

DISCUSSION: There is always curiosity about the features of new comer i.e. new born eg. color of skin, hair, and also about its wellness which they particularly relate with weight in minds, of parents as well as consultant. However the latter is interested in baby weight which he has tried to estimate in routine antenatal examination.

In our study, the ultrasound estimations of fetal weight were performed within 7 days prior to delivery.

Our study revealed that shephard formula showed an average mean weight of $2.81 \mathrm{kgs}$ with standard deviation of 0.5 while mean actual birth weight at the time of delivery was found to be 2.90 thus this shows a variability.

A study reveals that Shepard's equation is associated with a lower mean signed percent error ${ }^{12}$ though the mean difference found in estimation of fetal birth weight is small but cannot be stated accurate.

It was seen that Hadlock showed a mean weight of $2.54 \mathrm{~kg}$ whereas, mean weight at the time of delivery was 2.90 . 
In a study by Japarath et al from Thailand studied accuracy of fetal weight by clinical and sonography and concluded that intrapartum clinical estimation of fetal weight was as accurate as the ultrasonographic method. Ultrasonographic equation used was Hadlock's formula. ${ }^{13}$

It was found that average mean weight was $2.51 \mathrm{~kg}$ equivalent to average mean weight calculated by Hadlock but not equivalent to mean actual birth weight.

Study by Campbell implicated that routine screening of the obstetric population showed that with a single measurement at 32 weeks menstrual age, 87 percent of babies birth weight would be detected by this method but that the diagnosis of fetal birth weight rate would fall to 63 percent at 38 weeks, in our study singleton pregnancy above 36 weeks was studied and thus this formula doesn't reveal accurate findings. ${ }^{14}$

In our study Warsof formula predicted mean average weight of $1.4 \mathrm{~kg}$ which is far less than the mean of actual birth weight i.e. $2.90 \mathrm{~kg}$, that is why it is not to be used by sonologist.

In a study by Warsof showed that the abdominal circumference was the single best correlation with birth weight. ${ }^{15}$ But in our study Warsof showed greater difference when compared with actual birth weight.

Mean average weight was found to be $2.5 \mathrm{~kg}$ whereas mean average birth weight was found to be $2.90 \mathrm{~kg}$, not sufficient literature was found for comparison.

Dare's method showed an average mean weight of $2.88 \mathrm{~kg}$ which was highly comparable with the mean birth weight at the time of delivery i.e. $2.90 \mathrm{~kg}$.

Dare et al. tested this method on 498 full term patients and obtained a good correlation between the clinical estimate and actual birth weight. 16

Average mean weight by Johnson's formula came out to $2.89 \mathrm{~kg}$ which almost equivalent to mean birth weight i.e. $2.90 \mathrm{~kg}$, thus this method can be taken as reliable predictor for estimation of fetal birth weight. Carranza Lira $S$ et al evaluated the reliability of clinical and ultrasonographic measurements in fetal weight estimation during active delivery, as well as to define which is the best method for calculating it. ${ }^{17}$

Ashrafganjooei $\mathrm{T}$ et al compared the accuracy of ultrasound, clinical and maternal estimates of fetal weight in 246 parous women with singleton, term pregnancies. They concluded that abdominal palpation and Johnson's technique ${ }^{7}$ can be used as alternatives to ultrasound for estimation of fetal weight, particularly if the measurements are taken by experienced, skilled person. ${ }^{18}$

It was found that mean weight by Dawn's was $2.86 \mathrm{~kg}$ which is comparable to mean birth weight.

Various study done indicates that other clinical methods are more accurate that Dawn's Formula. ${ }^{19}$

Bhandary et al in 2004 from India compared methods of fetal birth weight estimation by four different methods Dare et al, Johnsons formula, Dawns formula and ultrasonographic by Hadlock and concluded that Dare et al's formula was the most accurate amongst the four. This finding is comparative to our study also. ${ }^{20}$

Akinolo et al compared the accuracy of clinical and ultrasonographic estimation of fetal weight at term it stated that Clinical estimation of birth weight is as accurate as routine ultrasonographic estimation, except in low-birth-weight babies. ${ }^{21}$ 
CONCLUSION: In developing countries like ours, it is important to remember that ultrasound fetal weight estimation requires expensive equipment and its time consuming for the hospital staff performing the examinations, who are often working in suboptimal condition and overcrowded maternity facilities. Requesting costly ultrasound estimates is hardly justifiable when clinical and maternal estimates are equally accurate and can be quickly carried out at no cost. Therefore, the finding in our study showing clinical methods to be better than ultrasound will be useful in our set up.

\section{REFERENCES:}

1. Barnhard Y, Bar-Hava I, Divon MY. Accuracy of intra partum estimates of fetal weight: Effect of oligohydramnios. J Reprod Med 1996;41:907-910.

2. Chauhan SP, Hendrix NW, Magann EF, Morrison JC, Jenney SP, Devoe LD. Limitations of clinical and sonographic estimates of birth weight: experience with 1034 parturients. ObstetGynecol 1998;91:72-7.

3. Nahum, Gerard G, Stanislaw, Harold. Ultrasonographic prediction of term birth weight: How accurate is it? American J Obstetrics \&Gyaneacol 2003; 188(2): 556-74.

4. Joseph Woo. A short History of the development of Ultrasound in Obstetrics and Gynecology. 1998-2001 access date Nov 04, 2004 available from www.yahoo.com.

5. Nzeh DA, Oyawoye 0, Adetoro 00. Ultrasound estimation of birth weight in late pregnancy among African women. West African J Ultrasound 2000;1:9-14.

6. Hendrix NW, Grady CS, Chauhan SP. Clinical versus sonographic estimation of fetal weight: a comparison with ultrasound. J Obstet Gynaecol 1990;10:199-201.

7. Campbell S, Dewhurst J. Diagnosis of small for dates fetus by serial ultrasound cephalometry. Lancet 1971;2:1002.

8. Sherman DJ, Arieli S, Tovbin J, Siegel G, Caspi E, Bukovsky IA. A comparison of clinical and ultrasound estimation of fetal weight. Obstet Gynaecol1998; 91:212-7.

9. Chauhan SP, Hendrix NW, Magann EF, Morrison JC, Jenney SP, DevoeLD. Limitations of clinical and sonographic estimates of birth weight: experience with 1034 parturients. Obstet Gynecol1998; 91:72-7.

10. Smellie Willam A. Treatise on the Theory and Practice of Midwifery London. 1766;206.

11. Thomas BN, Warren SB, Steven RC. Designing Clinical Research An Epidemiological Approach: Lippincott Williams \& Wilkins;2ndEd:pg 175.

12. Campbell WA, Vintzileos AM, Nochimson DJ. A comparison of two different ultrasound methods for estimating fetal weight in preterm gestations. J Clin Ultrasound. 1988 Sep;16(7):463-70.

13. Prechapanich J, Thitadilok W. Comparison of the Accuracy clinical and sonographic estimation of fetal weight. J Med Assoc Thai 2004;87(Suppl 3):S1-7.

14. Campbell S, Wilkin D. Ultrasonic measurement of fetal abdomen circumference in the estimation of fetal weight. Br J Obstet Gynecol. 197 Sept;82(9):689-97.

15. Warsof SL, Wolf P, Coulehan J, Queenan JT. Comparison of fetal weight estimation formulas with and without head measurements. Obstet Gynecol 1986; 67:569-73.

16. Dare FO, Ademowore AS, Ifaturoti 00, Nganwuchu A. The value of symphysio fundal height/abdominal girth measurement in predicting fetal weight. Int J Gynaecol Obstet1990; 31:243-8. 
17. Carranza Lira S, Haro Gonzalex LM, Biruete Correa B. Comparison between clinical and ultrasonographic measurements to estimate fetal weight during labour: A new clinical calculation formula. Ginecol Obstet Mex. 2007 Oct; 75(10):582-7.

18. Ashraf Ganjooei T, Naderi T, Eshrati B, Babapoor N. Accuracy of ultrasound, clinical and maternal estimates of birth weight in term women. East Mediterr Health J. 2010 Mar; 16(3): 313-7.

19. Deter RL, Hadlock FP. Use of ultrasound in the detection of macrosomia: a review. J Clin Ultrasound1985; 13:519.

20. Bhandary A, Pinto Patrick J, Shetty P. Comparative study of various methods of fetal weight estimation in term pregnancies. J Obstet Gynecol Ind. 2004 July/Aug; 54(5):336-339.

21. Shittu, Akinola S, Kuti, Oluwafemi, Orji, Ernest O, Makinde, Niyi O, Ogunniyi, Solomon O, Ayoola, Oluwagbemiga 0 and Sule, Salami S. Clinical Versus Sonographic Estimation of Fetal Weight in Southwest Nigeria The Journal of Health, Population and Nutrition, 2007;25(1):14-23.

\section{AUTHORS:}

1. Karuna Ratwani

2. Chandrakant S. Madkar

3. Hemant G. Deshpande

4. Sumit Jethani

\section{PARTICULARS OF CONTRIBUTORS:}

1. Resident, Department of Obstetrics and Gynaecology, Dr. D. Y. Patil Medical College, Pune.

2. Associate Professor, Department of Obstetrics and Gynaecology, Dr. D. Y. Patil Medical College, Pune.

3. Professor and Head, Department of Obstetrics and Gynaecology, Dr. D. Y. Patil Medical College, Pune.
4. Assistant Professor, Department of Community Medicine, Dr. D. Y. Patil Medical College, Pune.

\section{NAME ADDRESS EMAIL ID OF THE} CORRESPONDING AUTHOR:

Dr. Karuna Ratwani, L-306, Mahindra Royale Society, HA Corner, Nehrunagar, Pimpri, Pune - 411018.

E-mail: drkaruna@hotmail.com

Date of Submission: 02/02/2014.

Date of Peer Review: 03/02/2014.

Date of Acceptance: 19/02/2014.

Date of Publishing: 05/03/2014. 